\title{
Frequency of Peripheral Neuropathy in Newly Diagnosed Type 2 Diabetes Presenting in a Tertiary Care Hospital of Lahore
}

\author{
MUHAMMAD MUBASHAR TAHIR ${ }^{1}$, AIJAZ ZEESHAN KHAN CHACHAR ${ }^{2}$, MIQDAD HAIDER $^{3}$, AFAQ SHAMIM$^{4}$, MOHSIN \\ ASIF $^{5}$, SAJJAD ALI ${ }^{6}$, SAJJAD ALI ${ }^{7}$ \\ ${ }^{1,4}$ Post graduate resident, Department of Medicine, Fatima Memorial Hospital, Lahore \\ ${ }^{2}$ Senior Registrar, Medicine, Fatima Memorial Hospital College of Medicine \& Dentistry, Shadman, Lahore \\ ${ }^{3}$ Registrar, Social Security Hospital, Lahore \\ ${ }^{5}$ Registrar, Department of Medicine, Fatima Memorial Hospital, Lahore \\ ${ }^{6}$ Obesity Medicine and Infectious Diseases Physician, Sultan Bin Abdul Aziz Humanitarian City, Riyadh Saudi Arabia \\ ${ }^{7}$ Consultant Physician, Eastern Maine Medical Center USA \\ Correspondence to Dr. Aijaz Zeeshan Khan Chachar, Email; dr_aijaz84@hotmail.com
}

\begin{abstract}
Background: Among the common complications of diabetes, neuropathy has its place. About $50 \%$ of diabetics suffer from this complication. It is one of the most common cause of elevated morbidity mortality in diabetics. Duration of diabetes, its control and association with other micro vascular complications can result in an raised incidence of neuropathy in patients.

Aim: To find frequency of peripheral neuropathy in newly diagnosed type 2 diabetes in a tertiary care hospital.

Methods: Cross sectional study carried out in newly diagnosed patients with type II Diabetes Mellitus presented at department of Medicine, Fatima Memorial hospital, Lahore. 200 newly diagnosed type II diabetes patients who met the inclusion criteria were selected. Information was recorded on predesigned questionnaire regarding peripheral neuropathy and socio-demographic variables.

Results: The mean age among peripheral neuropathy respondents was $47.05 \pm 6.37$ years while it was $45.19 \pm 6.50$ years among not having peripheral neuropathy. Peripheral neuropathy was seen in $42(21 \%)$ respondents while in $158(79 \%)$ there was no peripheral neuropathy. Gender among peripheral neuropathy showed that males were 36 and females were 06 in number; and among non-peripheral neuropathy group there were 135 males and 23 females. Most of the low income respondents were suffering from peripheral neuropathy as compared to other income groups. Post stratification regarding age and gender yields significant results within income groups while the later showed only male respondents were significant.

Conclusion: This study reports that in type 2 diabetic patients diagnosed less than one year back, there is an increased prevalence of peripheral neuropathy. Male respondents were more in number than females but both had shown almost having same occurrence of peripheral neuropathy.

Keywords: Peripheral Neuropathy, Type II Diabetes, Neuropathy
\end{abstract}

\section{INTRODUCTION}

Diabetes mellitus (DM) is a major burden on public health worldwide as well as in Pakistan. The true prevalence is not known. As per WHO facts, 422 million people were suffering from diabetes in 2014 as compare to 108 million in 1980. ${ }^{1}$ Diabetes mellitus prevalence, according to WHO estimates is $8.5 \%$ of the world population in $2014^{2}$. In Pakistan, according to diabetes prevalence survey of Pakistan (DPSP) in 2017, 16.98\% prevalence was seen with $9.04 \%$ newly diagnosed and approx. 21.9 million were suffering from DM with age 20 \& above ${ }^{3}$. Type 2 diabetes is the most prevalent form of $\mathrm{DM}^{4}$.

Diabetes mellitus causes serious complications to the body systems as well. One of these complications is diabetic neuropathy. This is type of nerve damage that can occur mostly in legs and feet. Symptoms include pain, numbness in legs and feet. One of the most common type of diabetic neuropathy is peripheral neuropathy. It is combination of different heterogeneous disorders having wide etiological spectrum. The pathogenesis for diabetic peripheral neuropathy is multifactorial. Signs and symptom

Received on 11-02-2021

Accepted on 27-06-2021 include tingling and burning sensations, moderate to severe pains, loss of reflexes along with loss of balance and coordination etc ${ }^{5}$. They are usually worse at night. More than $60 \%$ of diabetics eventually develop neuropathy at some stage of their disease ${ }^{6}$.

The national level data not available, however studies from different hospital shows prevalence of peripheral neuropathy about $32.7 \%$ and $74.8 \%$ respectively. ${ }^{7,8}$ According to a study done by Mehwish Iftikhar et al in Lahore, Punjab Pakistan and found different variants of neuropathy like burning (62\%), numbness $(60.9 \%)$, tingling $(32.6 \%)^{8}$.

Lakhiar et al conducted a study in Karachi, Sindh Pakistan and found the prevalence of peripheral neuropathy patients was $32.7 \% .{ }^{7}$ Sonalika et al conducted study among Type 2 diabetes in Coastal Karnataka and found prevalence of neuropathy as $41.4 \%^{9,16}$.

Rationale of our study was to screen newly diagnosed Type 2 diabetes to determine the frequency of peripheral neuropathy. It has been known that there may be various risk factors of peripheral neuropathy and has significant impact on life of diabetic patients. But controversial evidence has been noticed from literature which showed the variables significance of association of peripheral neuropathy with various risk factors. Moreover, the above stated studies were obtained from local literature which 
contains ambiguity in results. So we wanted to conduct this study to confirm the extent of problem in local population and implement the results of this study in future. Furthermore strategies could be made to detect positive cases early to decrease the long term morbidity.

The objective of this study was to find the frequency of peripheral neuropathy in newly diagnosed type 2 diabetes presenting in a tertiary care hospital.

\section{OPERATIONAL DEFINITION:}

Peripheral Neuropathy: Patients were considered to have Peripheral neuropathy if they had loss of protective sensation in $\geq 8$ sites assessed using Weinstein $10 \mathrm{~g}$ monofilament test (annex) A. 'no' response on touching the filament was labeled as loss of protective sensation.

Newly Diagnosed Type 2 Diabetes Mellitus: Patients having blood sugar random(BSR) >200 $\mathrm{mg} / \mathrm{dl}$ (milligram/deci liter) diagnosed during last 1 year

\section{METHODOLOGY}

It was Cross sectional descriptive study conducted in the Department of Medicine Fatima Memorial Hospital, Lahore for a period of six months. Sample size of 200 patients was calculated with $95 \%$ confidence level, $7 \%$ margin of error and taking expected percentage of peripheral neuropathy i.e. $32.7 \%$. Sampling technique used was non probability consecutive sampling

Inclusion Criteria: Age from 30-60 years of any gender, Newly diagnosed type II diabetes less than 1 year

Exclusion Criteria: Patient with other diabetes type (I, Juvenile or Gestational) was excluded from this study, Patients with Rheumatoid arthritis, B12 deficiency, chronic musculoskeletal disease, alcohol abuse, Parkinson's disease, hypothyroidism, chronic renal (serum Creatinine> $1.3 \mathrm{mg} / \mu$ ), or liver failure (AST, ALT > $40 \mathrm{l} \mu / \mathrm{L}$ ) and cancer on medical record

Data collection procedure: There were total of 200 type 2 diabetic patients meeting the inclusion criteria coming to outpatient department of Medicine at Fatima Memorial hospital, Lahore were included in the study after informed consent. Demographic information (name, age, education and socioeconomic level) was also noted. Then Semmes Weinstein $10 \mathrm{~g}$ Monofilaments test was performed as per protocol. Responses were assessed and presence or absence of peripheral neuropathy was noted as per operational definition and all the findings were confirmed by the senior Consultant of the department along with a Consultant Neurologist. All this information was taken on proforma

Data analysis: IBM SPSS version 25.0 was used for data entry and data analysis. Quantitative variable was presented as mean and standard deviation like age. The qualitative variables were presented as frequency and percentage like gender, education, socioeconomic level and peripheral neuropathy. Chi square test was calculated to measure association of variables with peripheral neuropathy with $\mathrm{p}$ value $\leq 0.05$ was considered as significant. Effect modifiers including age and gender were controlled through stratification. Post stratification chi square test was calculated with $p$ value $\leq 0.05$ taken as significant.

\section{RESULTS}

The mean age among peripheral neuropathy respondents was $47.05 \pm 6.37$ years while it was $45.19 \pm 6.50$ years among not having peripheral neuropathy. Table 1.Gender among peripheral neuropathy showed that males were 36 and females were 06 in number; and among non-peripheral neuropathy group there were 135 males and 23 females (Table 1 ).

Education among peripheral neuropathy group showed that 08 were illiterate, 21 were having middle education, 06 had matric and 07 had higher education while in nonperipheral neuropathy group, there were 01 illiterate, 118 had passed middle, 26 had done matric and 13 had higher degrees (Table 1). Peripheral neuropathy was seen in $42(21 \%)$ respondents while in $158(79 \%)$ there was no peripheral neuropathy.

Peripheral neuropathy was found in 36 males, while 06 females had also peripheral neuropathy whereas 135 males had no peripheral neuropathy and among 23 females there was no peripheral neuropathy. The difference was statistically insignificant (0.965) (Table 1). Low income $(<15000)$ was found in 08 respondents who were suffering from peripheral neuropathy, middle income (15000-50000) having peripheral neuropathy were 21 and remaining 13 having peripheral neuropathy had high income (>50000) while among nonperipheral neuropathy respondents, 12 had Low income $(<15000), 117$ had middle income (15000-50000) and 29 had high income $(>50000)$. The difference was statistically significant (0.008) (Table 1).

Illiteracy was found in 08 respondents who were suffering from peripheral neuropathy, middle passed having peripheral neuropathy were 21,06 of the respondents had done matric that were suffering from peripheral neuropathy and remaining 07 having peripheral neuropathy had acquired higher degree while among non-peripheral neuropathy respondents, 01 was illiterate, 118 had passed middle, 26 had done matric and 13 had higher degrees. The difference was statistically significant $(<0.001)$ (Table 1$)$.

In respondent's $\leq 45$ years, there were 13 males having peripheral neuropathy and 58 were not having peripheral neuropathy while there were 03 females having peripheral neuropathy and 13 having no peripheral neuropathy. While in respondent's > 45 years, there were 23 males having peripheral neuropathy and 77 were not having peripheral neuropathy while there were 03 females having peripheral neuropathy and 10 having no peripheral neuropathy. Statistically significant difference was not found between the peripheral neuropathy with gender in patients with age $\leq 45$ years and with age $>45$ years. i.e., $p$-value $=0.967$ and $p$-value $=0.995$ respectively (Table 2 ). In respondent's $\leq 45$ years, there were 11 respondents not having peripheral neuropathy belonged to low socioeconomic status, 04 having peripheral neuropathy belonged to middle income group and 38 were having no peripheral neuropathy were in the same income group and there were 12 patients having peripheral neuropathy in higher income group and 22 were having no peripheral neuropathy in this higher income group. While in respondent's $>45$ years, there were 08 respondents having peripheral neuropathy belonged to low socioeconomic status and 01 in this income group was not having the disease, 17 having peripheral neuropathy belonged to middle income group and 79 were having no peripheral neuropathy in the same income group and lastly there was 01 patient having peripheral neuropathy in higher income group and 07 were having no peripheral neuropathy in this higher income group. Statistically significant difference was found between the peripheral 
neuropathy with income in patients with age $\leq 45$ years and with age $>45$ years. i.e., $p$-value $=0.004$ and $p$-value $=<0.001$ respectively (Table 2 ).

In male respondent's, regarding $\leq 45$ years age; there were 13 respondents having peripheral neuropathy and 58 were not having peripheral neuropathy whereas among $>45$ year there were 23 respondents having peripheral neuropathy and 77 were having no peripheral neuropathy. While in female respondent's, regarding $\leq 45$ years age; there were 03 respondents having peripheral neuropathy and 13 were not having peripheral neuropathy whereas among $>45$ year there were 03 patients having peripheral neuropathy and 10 were having no peripheral neuropathy. Statistically significant difference was not found between the peripheral neuropathy with age in patients with respect to their gender. i.e., pvalue $=0.459$ and $p$-value $=0.775$ respectively (Table 3 ). In male respondent's, there were 08 respondents having peripheral neuropathy belonged to low socioeconomic status and 09 respondents were having no peripheral neuropathy, 17 having peripheral neuropathy belonged to middle income group and 100 patients were having no peripheral neuropathy belonged to same income group and there were 11 patients having peripheral neuropathy in higher income group and 26 were having no peripheral neuropathy in this higher income group. While in female respondent's, there were 03 respondents having no peripheral neuropathy belonged to low socioeconomic status, 04 having peripheral neuropathy belonged to middle income group and 17 were having no peripheral neuropathy belonged to same income group and there were 02 patients having peripheral neuropathy in higher income group and 03 were having no peripheral neuropathy in this higher income group. Statistically significant difference was found between the peripheral neuropathy with income in male patients i.e., $p$-value $=0.003$ and no difference was found between females and income i.e., p-value $=0.377$ (Table 3 ).

Table-1: Comparison of age, Gender, Education level \& Income with Peripheral Neuropathy

\begin{tabular}{|l|l|c|c|c|}
\hline \multirow{2}{*}{} & \multicolumn{2}{|c|}{$\begin{array}{c}\text { Peripheral } \\
\text { Neuropathy }\end{array}$} & \multirow{2}{*}{} \\
\cline { 3 - 5 } \multicolumn{2}{|c|}{} & Yes & No & \\
\hline \multirow{2}{*}{ Age } & Mean & 47.05 & 45.19 & \multirow{2}{*}{0.088} \\
\cline { 2 - 4 } & SD & 6.37 & 6.50 & \\
\hline \multirow{3}{*}{ Gender } & Male & 36 & 135 & 0.965 \\
\cline { 2 - 4 } & Female & 06 & 23 & \\
\hline \multirow{4}{*}{ Education } & Illiterate & 08 & 01 & \multirow{2}{*}{0.001} \\
\cline { 2 - 4 } & Middle & 21 & 118 & \\
\cline { 2 - 4 } & Matric & 06 & 26 & \\
\cline { 2 - 4 } & Higher & 07 & 13 & \\
\hline \multirow{3}{*}{ Income } & Low $(<15000)$ & 08 & 12 & \multirow{2}{*}{0.008} \\
\cline { 2 - 4 } & Middle (15000-50000) & 21 & 117 & \\
\cline { 2 - 4 } & High (>50000) & 13 & 29 & \\
\hline \multirow{2}{*}{ Total } & & 42 & 158 & \\
\hline
\end{tabular}

Income* in Pakistani Rupees/ month

\begin{tabular}{|c|c|c|c|c|c|}
\hline \multirow{2}{*}{ Age (years) } & \multirow{2}{*}{ Gender } & \multicolumn{2}{|c|}{ Peripheral Neuropathy } & \multirow{2}{*}{ Total } & \multirow{2}{*}{$p$-value } \\
\hline & & Yes & No & & \\
\hline \multirow{2}{*}{$\leq 45$} & Male & 13 & 58 & 71 & \multirow{2}{*}{0.967} \\
\hline & Female & 03 & 13 & 16 & \\
\hline \multirow{2}{*}{$>45$} & Male & 23 & 77 & 100 & \multirow{2}{*}{0.995} \\
\hline & Female & 03 & 10 & 13 & \\
\hline \multirow{3}{*}{$\leq 45$} & Low $(<15000)$ & 00 & 11 & 11 & \multirow{3}{*}{0.004} \\
\hline & Middle (15000-50000) & 04 & 38 & 42 & \\
\hline & High $(>50000)$ & 12 & 22 & 34 & \\
\hline \multirow{3}{*}{$>45$} & Low $(<15000)$ & 08 & 01 & 09 & \multirow{3}{*}{0.001} \\
\hline & Middle (15000-50000) & 17 & 79 & 96 & \\
\hline & High $(>50000)$ & 01 & 07 & 08 & \\
\hline
\end{tabular}

Table-3: Comparison of Age with Peripheral Neuropathy Stratified by Gender

\begin{tabular}{|c|c|c|c|c|c|}
\hline \multirow{2}{*}{ Gender } & \multirow{2}{*}{ Age (years) } & \multicolumn{2}{|c|}{ Peripheral Neuropathy } & \multirow{2}{*}{ Total } & \multirow{2}{*}{$\mathrm{p}$-value } \\
\hline & & Yes & No & & \\
\hline \multirow{2}{*}{ Male } & $\leq 45$ & 13 & 58 & 71 & \multirow[b]{2}{*}{0.459} \\
\hline & $>45$ & 23 & 77 & 16 & \\
\hline \multirow{2}{*}{ Female } & $\leq 45$ & 03 & 13 & 16 & \multirow{2}{*}{0.775} \\
\hline & $>45$ & 03 & 10 & 13 & \\
\hline \multirow{3}{*}{ Male } & Low $(<15000)$ & 08 & 09 & 17 & \multirow{3}{*}{0.003} \\
\hline & Middle (15000-50000) & 17 & 100 & 117 & \\
\hline & High $(>50000)$ & 11 & 26 & 37 & \\
\hline \multirow{3}{*}{ Female } & Low $(<15000)$ & 00 & 03 & 03 & \multirow{3}{*}{0.377} \\
\hline & Middle (15000-50000) & 04 & 17 & 21 & \\
\hline & High $(>50000)$ & 02 & 03 & 05 & \\
\hline
\end{tabular}

\section{DISCUSSION}

Diabetes mellitus (DM) is a one of the most common endocrine condition and a global health problem. It is associated with many complications, which can be divided into micro and macro vascular complications. The microvascular complications include neuropathy, nephropathy, and retinopathy. Neuropathy is the complication most commonly seen in Medical, Neurology and Endocrine OPD among diabetic patients. There is limited data available on its incidence, prevalence and association in our settings. This was the main purpose of this study, to study and document the prevalence of diabetic neuropathy in newly diagnosed diabetics. In this study, we evaluated the prevalence of the condition in diabetic patients. We also determined the association of various patient related variables with peripheral neuropathy.

Frequency of neuropathy among newly diagnosed cases of Type 2 Diabetes was found to be $21 \%$ in this study. There was another study conducted by Gill $\mathrm{HK}$ et $\mathrm{al}^{17}$ which concluded that $29.2 \%$ of the studied population had diabetic peripheral neuropathy, which is different from results of our study. Iftikhar et al in their study demonstrated that $74.8 \%$ of patients had neuropathy, it is a significantly high number as compared to our study. These high figures can be explained as in this study, patients with duration of Diabetes of more than 20 years were included ${ }^{18}$. Various studies done in different 
countries of the world including Saudia Arabia and United Arab Emirates have shown the prevalence of diabetic peripheral neuropathy to be 45 and 29.2 percent $^{19-21}$. There are various factors which can explain these differences of figures among different studies. One factor is the type of filament used. Some researchers have used Semmes Weinstein $10 \mathrm{~g}$ Monofilament Test and others have used a biothesiometer, there sensitivities vary $^{22}$. There are some studies which have shown interesting results, like those done in Hong Kong and India which showed diabetic nephropathy as the most frequent complication among all the microvascular complications of Diabetes Mellitus ${ }^{25,26}$

In current study patients' mean age among peripheral neuropathy respondents was $47.05 \pm 6.37$ years while it was $45.19 \pm 6.50$ years among not having peripheral neuropathy; Gender among peripheral neuropathy showed that males were 36 and females were 06 in number; and among non-peripheral neuropathy group there were 135 males and 23 females. No notable impact of age or sex was found in our study however a study completed by Gogia et al found that male had a higher incidence in Bansal et al found that there was no significant difference among members of both genders ${ }^{28,29}$.

\section{CONCLUSION}

This study reports high prevalence of peripheral neuropathy in type 2 diabetic patients diagnosed less than one year back. Male respondents were more in number than females but both had shown almost having same occurrence of peripheral neuropathy. The income of the respondents showed a significant statistical difference with age, education and regarding gender only males had shown difference.

\section{Semmes Weinstein 10g Monofilament Test}
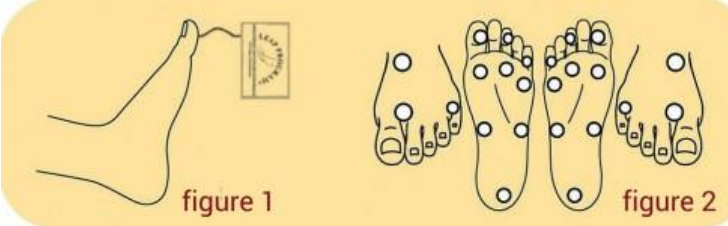

Score:

\section{REFERENCES}

1. WHO. Diabetes Key Facts. [Online] Cited on: November, 15, 2017. Accessed on: June, 25, 2018. Available from: http://www.who.int/news-room/fact-sheets/detail/diabetes.

2. Mathers CD, Loncar D. Projections of global mortality and burden of disease from 2002 to 2030. PLoS Med, 2006, 3(11):e442.

3. The news. Diabetes Prevalence Data in Pakistan $35.3 \mathrm{~m}$ adult population diabetic in country: survey. [Online] Cited on: November, 26, 2017. Accessed on: 25-02-2020. Available from: https://www.thenews.com.pk/print/248882-diabetes-prevalence-datain-pakistan-35-3m-adult-population-diabetic-in-country-survey.

4. Kim SM, Lee JS, Lee J, Na JK, Han JH, Yoon DK, et al. Prevalence of diabetes and impaired fasting glucose in Korea: Korean National Health and Nutrition Survey 2001. Diabetes Care. 2006; 29:226-31.

5. Mayoclinic. Diabetic Neuropathy. [Online] Cited on: May, 16, 2018. Accessed on: 25-02-2020. Available from: https://www.mayoclinic.org/diseases-conditions/diabeticneuropathy/symptoms-causes/syc-20371580.

6. Webmd. Peripheral Neuropathy and Diabetes. [Online] Cited on: May, 15, 2018. Accessed on: June, 25, 2018. Available from https://www.webmd.com/diabetes/peripheral-neuropathy-risk-factorssymptoms\#1.

7. Lakhiar MA, Shahbaz NN, Bughio AH, Prakash J. Frequency of peripheral neuropathy in newly diagnosed patients of diabetes mellitus iion clinical and electrophysiological basis. PJNS 2014: 9(4): 31-35.
8. Iftikhar M, Hussain A, Rizvi A. Frequency of Peripheral Neuropathy in Patients with diabetes mellitus. J Ayub Med Coll Abbottabad 2014;26(4):584-6.

9. Gogia S, Rao CR. Prevalence and Risk Factors for Peripheral Neuropathy among Type 2 Diabetes Mellitus Patients at a Tertiary Care Hospital in Coastal Karnataka. Indian J EndocrinolMetab. 2017 Sep-Oct; 21(5): 665-669.

10. WHO media centre Diabetes fact sheet no 312, [online]. 2011[January 2011]; Available from: URL: http//www.who.int/ entity/ mediacentre/factsheets/fs 312/en/index.html

11. Shamim AR, Haq AR, Ali MA. Prevalence of Peripheral diabetic Neuropathy and its Association with patients related factors. Pak J Med Health Sci. 2017 Jul. 1; 11: 1130-2.

12. Tesfaye S, Selvarajah D. Advances in the epidemiology, pathogenesis and management of diabetic peripheral neuropathy. Diabetes Metab Res Rev. 2012; 28: 8-14.

13. Yoo M, Sharma N, Pasnoor M, Kluding PM. Painful Diabetic Peripheral Neuropathy: Presentations, Mechanisms, and Exercise Therapy. J Diabetes Metab. 2013; S10: 005

14. Arshad AR, Alvi KY. Diagnostic accuracy of clinical methods for detection of diabetic sensory neuropathy. Journal of the College of Physicians and Surgeons Pakistan, 2016; 26 (5): 374-9.

15. Gupta A, Gupta Y. Diabetic neuropathy: Part 1. J Pak Med Assoc. 2014; 64: 714-8.

16. Callaghan BC, Cheng HT, Stables CL, Smith AL, Feldman EL. Diabetic neuropathy: clinical manifestations and current treatments. Lancet Neurol. 2012; 11: 521-34.

17. Gill HK, Yadav SB, Ramesh V, Bhatia E. A prospective study of prevalence and association of peripheral neuropathy in Indian patients with newly diagnosed type 2 diabetes mellitus. J Postgrad Med. 2014; 60 (3): 270-280.

18. Iftikhar M, Hussain A, Rizvi A. Frequency of peripheral neuropathy in patients with diabetes mellitus. Journal of Ayub Medical College Abbottabad, 2014; 1; 26 (4): 584-6.

19. Khawaja N, Abu-Shennar J, Saleh M, Dahbour SS, Khader YS, Ajlouni $\mathrm{KM}$. The prevalence and risk factors of peripheral neuropathy among patients with type 2 diabetes mellitus; the case of Jordan. Diabetology\& metabolic syndrome, 2018; 10 (1): 8.

20. Al-Geffari M. Comparison of different screening tests for diagnosis of diabetic peripheral neuropathy in Primary Health Care setting. Int $\mathrm{J}$ Health Sci. 2012; 6: 127-34.

21. Tabatabaei-Malazy O, Mohajeri-Tehrani MR, Madani SP, Heshmat R, Larijani B. The prevalence of diabetic peripheral neuropathy and related factors. Iran J Public Health, 2011; 40: 55-62.

22. Al-Kaabi JM, Al-Maskari F, Zoubeidi T, Abdulle A, Shah SM, Cragg P, Afandi B, Souid A. Prevalence and determinants of peripheral neuropathy in patients with type 2 diabetes attending a tertiary care center in the United Arab Emirates. J Diabetes Metab. 2014; 5: 346.

23. Ashok S, Ramu M, Deepa R, Mohan V. Prevalence of neuropathy in type 2 diabetic patients attending a diabetes centre in South India. JAPI. 2002; 50: 546-50.

24. Pradeepa $R$, Anjana RM, Unnikrishnan R, Ganesan A, Mohan V, Rema M. Risk factors for microvascular complications of diabetes among South Indian subjects with type 2 diabetes-the Chennai Urban Rural Epidemiology Study (CURES) eye study-5. Diabetes TechnolTher. 2010; 12(10):755-61.

25. Pradeepa R, Rema M, Vignesh J, Deepa M, Deepa R, Mohan V. Prevalence and risk factors for diabetic neuropathy in an urban south Indian population: the Chennai urban rural epidemiology study (CURES-55). Diabet Med. 2008; 25(4):407-12.

26. Wani FA, Koul RK, Raina AA, Nazir A, Maqbool M, Bhat MH, et al Prevalence of microvascular complications in newly diagnosed type-2 diabetes mellitus. Int J Sci Study. 2016; 3(10):102-5.

27. Ather NA, Sattar RA, Ara J. Frequency ofsensorymotor Neuropathy in type 2 Diabetes. JDUHS. 2008; 2 (1): 27-31.

28. Gogia S, Rao CR. Prevalence and risk factors for peripheral neuropathy among type 2 diabetes mellitus patients at a tertiary care hospital in coastal Karnataka. Indian journal of endocrinology and metabolism, 2017; 21 (5): 665

29. Bansal D, Gudala K, Muthyala H, Esam HP, Nayakallu R, Bhansali A Prevalence and risk factors of development of peripheral diabetic neuropathy in type 2 diabetes mellitus in a tertiary care setting. J Diabetes Investig. 2014; 5: 714-21. 